\title{
Biomarkers of micronutrient status
}

\author{
Susan J. Fairweather-Tait* \\ School of Medicine Health Policy \& Practice, University of East Anglia, Norwich NR4 7TJ, United Kingdom
}

An international workshop of invited experts and partners in the EC-funded Network of Excellence, EURRECA (www. eurreca.org) was held in Norwich on 18-20 February 2008 to discuss biomarkers of micronutrient status. The primary objective of EURRECA is to generate scientific outputs ('tools') that can be used to harmonise micronutrient recommendations across Europe, with special focus on vulnerable groups. The workshop was organised by Work Package RA1.2 (Biomarkers of Status), led by the University of East Anglia, whose main activity is to review all available published literature for priority micronutrients and publish systematic reviews that describe the best measures of status that are currently available. This information will be invaluable for committees setting dietary reference guidelines and will contribute to the revised population reference intakes that the European Food Safety Authority (EFSA) Panel on dietetic products, nutrition and allergies (http://www.efsa.europa. eu/EFSA/ScientificPanels/efsa_locale-1178620753812 _NDA. $\mathrm{htm}$ ) will be undertaking later this year under the mandate of the Directorate General for Health and Consumer Affairs (DGSANCO) (http://ec.europa.eu/health/index_en.htm).

Invited experts from around the world gave presentations on a number of micronutrients, critically reviewing traditional biomarkers that are employed in surveys and the application of post-genomic technologies for the development of novel biomarkers and the development of a network biology model of micronutrient related health, which may be utilized in future dietary guidelines. Partners from EURRECA provided updates on progress on their systematic reviews and, for the benefit of the invited experts, Dr Lee Hooper (Senior Lecturer in research synthesis and nutrition at UEA) explained the methodology that had been developed for the systematic reviews. The plan is to include a full description of this as part of the first collection of systematic reviews, which we hope to submit for publication in the autumn of this year.

The papers relating to the presentations included in this supplement cover a variety of micronutrients and issues relating to the measurement of status. As such, they are an excellent reference source for anyone interested in the relationship between diet and health, and, more specifically, methods for assessing the impact of micronutrient intake on health. Further information on nutritional assessment can be obtained from the recently revised and updated comprehensive reference book written by Professor Rosalind Gibson ${ }^{(1)}$.

Nutritional status, when applied to specific micronutrients, reflects a continuum, from short-term (hours) exposure (which is mainly the domain of phytochemicals and micronutrients for which we have no biochemical/functional markers) to long-term (months/years) effects. As a consequence, there are a large number of laboratory measures that are employed to assess dietary adequacy, the primary criterion for usefulness being the ability to obtain the relevant biological sample e.g. blood, urine and faeces. Examples of types of status biomarkers include plasma concentration, the size of body pools, enzyme levels and activities, urinary excretion and a range of other biochemical and/or functional indicators which have varying degrees of specificity and sensitivity. For anyone working in this field, it is clear that there is a pressing need to develop improved biomarkers of status for many micronutrients, and it is hoped that the new approaches mentioned in the papers in this supplement will lead the way.

\section{Reference}

1. Gibson RS (2005) Principles of Nutritional Assessment, 2nd ed. New York: Oxford University Press. 